\title{
COMFORT-RELATED PROPERTIES OF DOUBLE-LAYERED WOVEN CAR SEAT FABRICS
}

\author{
Pelin Gürkan Ünal' ${ }^{1}$, Gonca Özçelik Kayseri' ${ }^{2, *}$, H. Diren Mecit $^{3}$ \\ 1 Namık Kemal University, Department of Textile Engineering, Tekirdağ, Turkey \\ 2 EmelAkın Vocational High School, Ege University, Izmir, Turkey \\ 3 Martur R\&D Manager, Bursa, Turkey \\ *Corresponding author E-mail: goncaozcelikkayseri@gmail.com
}

\begin{abstract}
:
Seat upholstery fabrics for vehicles are crucial products as technical textiles in motor vehicles make up approximately $15 \%$ of the total manufactured technical textiles worldwide and more than $50 \%$ of the production belongs to the woven fabrics because of their appropriate properties for this application.

The current work presents the comfort-related properties of the woven fabrics designed to be used in automotive seat upholstery. For this aim, double-layered woven fabrics were produced with four different process variables such as bottom layer pattern, number of interlacing warps in a unit report, number of interlacing picks per top warp, and number of weft skips by using Taguchi experimental design. Besides handle related properties, such as circular bending rigidity, surface roughness properties, and thermo physiological comfort related properties that include air permeability, thermal resistance, and moisture management properties were measured and analyzed based on Taguchi experimental analysis.
\end{abstract}

\section{Keywords:}

Car seat fabric; double-layered woven fabric; handle; thermo physiological comfort; moisture management

\section{Introduction}

Today, the average car has approximately $30 \mathrm{~kg}$ of textiles and this is a growing trend, as high-performance and intelligent fibers, yarns, and compound materials are assuming an ever increasing number of comfort, safety, acoustic, and fuel-saving functions with the development of lightweight constructions. Automotive textile materials are used for various applications such as fabrics for passenger safety, airbags, and safety belts, fabrics for passenger comfort of car seat covers and car interior design, as well as for different filters built in motor vehicles [1]. Textiles provide a means of decoration and a warm soft touch to the seats and the interior of the car, but they are also used in more functional applications. Carpets and textile headliners not only contribute to the overall comfort and decor of the interior, but they also play an important role in damping of sound and vibration [2].

The three main fabric-forming structures that have a place in automotive manufacturing are woven, knitted, and nonwoven, and among these structures, interior automotive fabrics produced by weaving technology dominate this sector with $51 \%$. Each technology has advantages and limitations, and car manufacturers use consumer's criteria or priorities for different fabrics. Fabrics produced by weaving are mainly dobby weaves having $32 \%$ of the share, followed by jacquard weaves with $18 \%$ which shows an increasing trend nowadays. Jacquard and dobby-designed fabrics are mainly used in the seat area whereas the dobby woven plain fabric are used in the seat wings, bolsters, and rear covers of the front seats [3].

Some of the most stringent performance requirements in the textile industry are enforced by vehicle manufacturers on their fabric suppliers. The main criteria involved in the development of textiles and components in automotive are: tensile strength, abrasion resistance, pill resistance, air permeability, compression resistance, elasticity, light fastness at high temperatures, stiffness, ease of cleaning, separation force, dimensional stability, flame resistance, certain friction factor, antistatic property, anti-fogging resistant, and resistance to adverse climatic conditions. The others processing requirements are mold ability, susceptibility to compression, sew ability, weld ability, adhesive properties, vulcanizing properties [4-7]. In car production, the development of components, parts, pieces and materials is orientated by comfort, functionality, safety, and economy and ecology criteria [8]. Comfort in a car is a complex phenomenon and comprises such different aspects as, for example, noise, driving behavior, or ease of handling. 
The comfort is the first criterion that values the customer, specifically psychological comfort-makes reference to the esthetic aspects-and physiological comfort captured by the view and touch. Thermo-physiological comfort is not just a pleasant feeling while sitting as it improves the performance and concentration of drivers [9].

Automotive car seats are constructed by mainly three elements, such as metal structure, filling material that includes molded polyurethane foam and seat cover, and exterior fabric, foam and support material as reinforcement part. Fabric, which is mostly used for the car seats, is polyester with high abrasion resistance, UV light resistance and cleaning facility combined together with a reasonable price, but the disadvantage is that it neither absorbs nor transports humidity. The inner layer of foam varies from few millimeters to $12 \mathrm{~mm}$, and its cushioning effect absorbs the seat surface irregularities, improves the comfort (compressibility, resilience), and indicates the stitches of the sewing lines with an adequate depth. The reinforcement material has the task to give the dimensional stability to sandwich structure and facilitates the sewing and seam resistance. It can be a polyamide mesh or polyester and a nonwoven as well. These three layers, fabric-foam-reinforcement, are fixed by flame laminate $[2,3,5,10]$.

In the literature, there are a few studies examining the handleand comfort-related properties of the textiles used exteriorly for automobile seat covers. These studies generally focus on the properties of the fabrics that are commonly used in the market. Simiona et.al analyzed the factors that influencing thermal comfort inside the vehicles. In the study, the factors were classified in two classes: measurable factors, including air temperature, air velocity, radiant temperature and relative humidity and personal factors including activity level and clothing insulation. Based on these factors predicted mean vote (PMV) representing the average thermal sensation felt by a group of people sitting in the vehicle was determined [11]. El Homassani et.al investigated the impact of automotive fabrics made of chenille yarns containing PCMs on the properties relating to comfort and concluded that increasing $\mathrm{PCM}$ percentage in the produced fabrics lead to an increase in thermal comfort of car seat fabrics and suggested using PCMs for improving the comfort properties with little energy cost, resulting in reduced air conditioning and fuel consumption [10]. Havelka et.al investigated the performance of car seat fabrics in terms of physiological comfort of sitting, specifically the water vapor resistance and air permeability properties were determined and presented an alternative approach to increase the effectiveness of car seat fabrics through a combination of newly designed middle layer with forced convection achieved by a supplementary suction ventilation device. The results showed that water vapor transport was increased by approximately $20 \%$ compared to the standard way of measurement by means of SGHP because of forced air flow in the plane of ribbedchanneled structure in the middle layer of car seat [9]. In a study, the relationship between abrasion and tensile strength properties of automobile seat fabrics was examined. It was found that the increase in the number of cycles reduced the strength of the fabric in a systematic manner [12]. Pamuk and Çeken examined the changes in thickness and weight values of automobile seat cover fabrics after 10,000 rubs of abrasion [13]. Ujevic et.al examined chemical, physical, and mechanical properties of artificial leather lined with a textile fabric on the backside. Samples of artificial leather with woven fabrics on the backside had a greater breaking force than samples of artificial leather with knitted fabric on the backside, in the warp, longitudinal, and weft directions, whereas in other diagonal directions artificial leather with knitted fabric on the backside have higher breaking forces [14]. Cengiz and Babalık compared the ramie blended fabrics with the polyester fabrics in terms of their thermal comfort properties. It was found that cars with ramie blended seat covers were more comfortable based on the subjective evaluation collected from a questionnaire of five questions and these results were consistent with the objective measurements [15]. Jerkovic et.al examined Martindale, Schopper, and Transverse abrasion resistance testers and the methods were compared with each other using P320, P400, P600 abrasive papers [16]. Mecit et.al investigated automotive industry applications for recyclable products. Two different fabrics with different yarn linear densities and constructions were produced with recycled and virgin fibers and their properties were tested in accordance with the automotive requirements. As a result of the study, it was found that the values obtained by using recycled fibers were in the acceptable range in terms of customer satisfaction despite some differences in yarn and fabric test results [17]. Koc et.al investigated the effect of filament cross section on automotive upholstery fabric performance in detail [18]. Avcu and Gürkan investigated the mechanical performances of double-layered woven fabrics used in car seat upholstery by measuring tear strength, breaking strength, and abrasion properties [19].

This study is distinguished from previous studies in terms of the development of double- layered woven fabrics with high mechanical properties aimed to be used use in automotive seat upholstery and investigated in terms of comfort related properties.

\section{Experimental}

\subsection{Materials}

In this study, by changing fabric production parameters, double-layered woven fabrics in various structures were produced. For the production of fabrics, warp of the top layer was connected with the weft of the bottom layer and so full weft connection was used. By changing four parameters in three different levels, double-layered woven fabrics were produced based on L9 (3 levels 4 factor) Taguchi experimental design. Instead of producing 81 different double-layered woven fabrics with a full factorial design, which is very difficult to manufacture, only 9 different types of double-layered woven fabrics were manufactured by using Taguchi design. The factors and levels used to produce double-layered woven fabrics were presented in Table 1 and the technical production characteristics of the fabrics were presented in Table 2.

The theoretical warp density was 28 threads/cm (14+14 for top and bottom) and the theoretical weft density was 34 picks $/ \mathrm{cm}$ for 
Table 1. Factor and parameter levels of the manufactured fabrics

\begin{tabular}{|c|c|c|c|c|}
\hline Factor level & Bottom layer pattern & $\begin{array}{c}\text { Number of interlacing } \\
\text { warps in a unit report }\end{array}$ & $\begin{array}{c}\text { Number of interlacing } \\
\text { picks per warp }\end{array}$ & $\begin{array}{c}\text { Number of weft } \\
\text { skips }\end{array}$ \\
\hline I & Twill 2/2 Z & 1 & 2 & 0 \\
\hline II & Panama 2/2 & 2 & 3 & 1 \\
\hline III & Warp ribs 2/2 & 3 & 4 & 2 \\
\hline
\end{tabular}

Table 2. Manufactured fabrics and levels of the related parameters

\begin{tabular}{|c|c|c|c|c|}
\hline $\begin{array}{c}\text { Fabric } \\
\text { number }\end{array}$ & $\begin{array}{c}\text { Bottom layer } \\
\text { pattern }\end{array}$ & $\begin{array}{c}\text { Number of interlacing warps } \\
\text { in a unit report }\end{array}$ & $\begin{array}{c}\text { Number of interlacing } \\
\text { picks per warp }\end{array}$ & $\begin{array}{c}\text { Number of weft } \\
\text { skips }\end{array}$ \\
\hline $\mathrm{F} 1$ & $\mathrm{I}(\mathrm{T} 2 / 2 \mathrm{Z})$ & $\mathrm{I}(1)$ & $\mathrm{I}(2)$ & $\mathrm{I}(0)$ \\
\hline $\mathrm{F} 2$ & $\mathrm{I}(\mathrm{T} 2 / 2 \mathrm{Z})$ & $\mathrm{II}(2)$ & $\mathrm{II}(3)$ & $\mathrm{II}(1)$ \\
\hline $\mathrm{F} 3$ & $\mathrm{I}(\mathrm{T} 2 / 2 \mathrm{Z})$ & $\mathrm{III}(3)$ & $\mathrm{II}(4)$ & $\mathrm{II}(2)$ \\
\hline $\mathrm{F} 4$ & $\mathrm{II}(\mathrm{P} 2 / 2)$ & $\mathrm{I}(1)$ & $\mathrm{II}(3)$ & $\mathrm{III}(2)$ \\
\hline $\mathrm{F} 5$ & $\mathrm{II}(\mathrm{P} 2 / 2)$ & $\mathrm{II}(2)$ & $\mathrm{II}(4)$ & $\mathrm{I}(0)$ \\
\hline $\mathrm{F} 6$ & $\mathrm{II}(\mathrm{P} 2 / 2)$ & $\mathrm{III}(3)$ & $\mathrm{I}(2)$ & $\mathrm{II}(1)$ \\
\hline $\mathrm{F} 7$ & $\mathrm{III}\left(\mathrm{R}_{\mathrm{w}} 2 / 2\right)$ & $\mathrm{I}(1)$ & $\mathrm{I}(2)$ & $\mathrm{I}(1)$ \\
\hline $\mathrm{F} 8$ & $\mathrm{III}\left(\mathrm{R}_{\mathrm{w}} 2 / 2\right)$ & $\mathrm{II}(2)$ & $\mathrm{II}(3)$ & $\mathrm{III}(2)$ \\
\hline $\mathrm{F} 9$ & $\mathrm{III}\left(\mathrm{R}_{\mathrm{w}} 2 / 2\right)$ & $\mathrm{III}(3)$ & $\mathrm{I}(0)$ \\
\hline
\end{tabular}

top and bottom layers $(17+17$ for top and bottom layer). Since 34 picks/cm was not possible for F5, the weft density was set to 26 picks/cm (13+13 for top and bottom layer). Four parameters were determined in order to produce double-layered woven fabrics. One of the parameters was the pattern of the bottom layer which was chosen as Twill $2 / 2 \mathrm{Z}$, Panama $2 / 2$, and Ribs $2 / 2$ based on the commonly used patterns in the production of automotive seat covers, while top layer pattern was set to Twill $2 / 2 \mathrm{Z}$. Top and bottom layers of the fabrics were attached with the intersection of top warp and bottom weft as shown in Figure 1(b); diagonal lines in the circle means that top warp yarns are under the bottom weft yarns. When such an intersection was a topic, three different parameters were considered. The first parameter was the number of the warp threads of top layer intersecting in a unit report. Three levels were determined for this parameter $(1,2$, and 3$)$. This parameter was represented in
Figure 1 (b), (c), and (d), respectively. In Figure 1(b), there was only one top layer warp yarn intersecting with the bottom layer weft yarns. In Figure 1(c) and (d), the number of intersecting warps in a unit report was 3 and 2, respectively. The second parameter was the number of the intersection of the bottom layer with warp of the top layer in a unit report. For this parameter, three levels such as 2, 3, and 4 were determined as shown in Figure 1(b), (c), and (d), respectively and number of interlacing picks per warp yarn was 2 in all of them. The third parameter expressed whether the warp yarn of the top layer was consecutively under the weft yarns of the bottom layer or not. For this parameter, three levels such as 0,1 , and 2 were determined. This means that if the number of weft skips was " 0 " then the warp yarn of the top layer was consecutively under the weft yarn of the bottom layer as illustrated in Figure 1(b). On the other hand, if this value was set to " 1 " then this meant that there

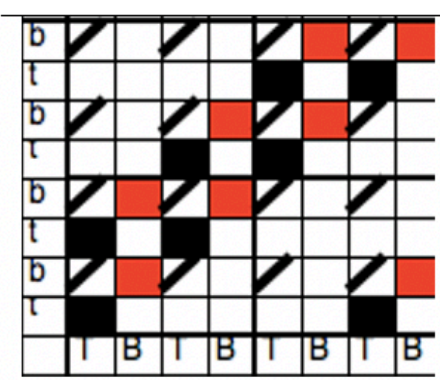

a.

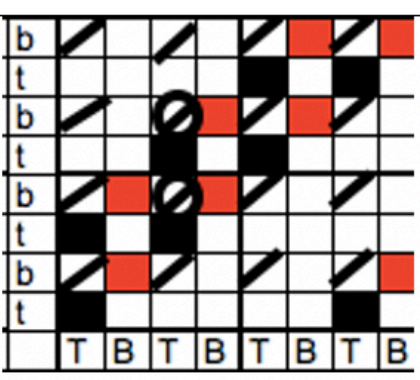

b.

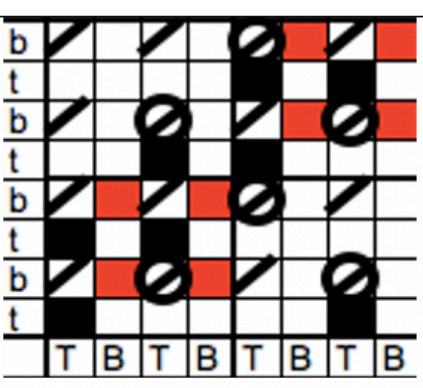

c.

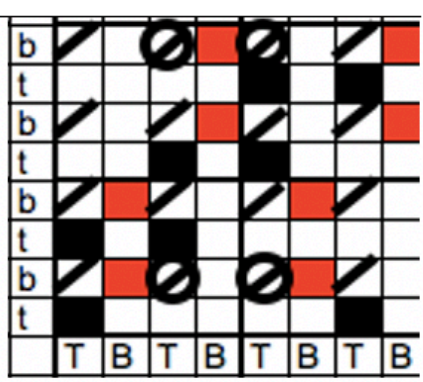

d.

Figure 1. Schematic diagrams of double-layered fabrics produced in the study (T: for top layer warp, B: for bottom layer warp, t: for top layer weft, and b: for bottom layer weft); (a) The unit pattern of the double-layered fabrics without intersections (diagonal lines represent that warp yarns of the top surface are over the weft yarns of the bottom surface), (b) unit pattern of the double-layered fabric F1 (diagonal lines in the circles mean that warp yarns of the top surface are under the weft yarns of the bottom surface), and (c) unit pattern of the double-layered fabric F6, and (d) unit pattern of the double-layered fabric F8. 
was a "1" skip between the linking of the warp yarn of top layer with weft yarns of bottom layer (Figure 1(c)). The difference between "0" and "1" weft skip can be observed from Figures 1 (b) and (c). Finally, if this value was set to "2", meaning that there were "2" skips between the linking of the warp yarn of top layer with weft yarns of bottom layer (Figure 1(d)).

After the production of the fabrics, all the fabrics were stentered, which is an essential and inevitable finishing phase in the production of the seat covers. Stentering provides a stable, flat, tension free substrate for lamination and eventual seat fabrication and this process affects the mechanical properties of the fabrics $[2,19,20]$. Stenter consisted of 6 chambers and in each chamber the temperature was $160^{\circ} \mathrm{C}$. Initial and final width of the fabric was set to 124 and $140 \mathrm{~cm}$, respectively and fabric-passing speed was $10 \mathrm{~m} / \mathrm{min}$.

\section{$\underline{2.2 \text { Methods }}$}

All fabric samples were conditioned for $24 \mathrm{~h}$ under a laboratory environment at $20 \pm 2^{\circ} \mathrm{C}$ and $65 \pm 5 \%$ relative humidity.

For the handle properties, circular bending rigidity, roughness, and surface friction coefficient measurements were performed. As for thermo-physiological comfort related properties, thermal resistance, air permeability, and dynamic moisture transport measurements were determined.

Circular bending rigidity values of the fabrics were measured by circular bending tester developed according to ASTM D 4032 [21]. Three specimens in the dimensions of $20 \times 10 \mathrm{~cm}$ were prepared for the measurement of bending rigidity in multiaxial directions. In this method, the force which is generated while pushing a fabric specimen through a ring is measured and read from the digital indicator.

Surface roughness characteristics of the fabrics were determined by using Surftest SJ-310 roughness tester according to ISO 4287 (Figure 2) [22, 23]. The stylus of the instrument detector unit traces the minute irregularities of the fabric surface and at least 20 roughness parameters can be obtained. From these parameters commonly used ones $R_{a}$ and $R_{z}$ values were evaluated in this study. $R_{a}$ is the most useful and frequent parameter for analyzing the surface structure. It is the arithmetical average of the absolute values of the profile variations (Equation 1). The sum of the maximum profile peak height and the maximum profile valley depth in one sampling length is defined as $R_{z}$ (Equation 2). This parameter is approximately equal to the structural roughness of the fabric surface.

$$
\begin{aligned}
& R_{a}=\frac{\left|Z_{1}+Z_{2}+\ldots \ldots+Z_{n}\right|}{n} \\
& R_{z}=Z_{p}+Z_{v}
\end{aligned}
$$

In woven fabrics, $R_{z}$ changes with differences in construction. While $R_{a}$ is useful in quality control, it does not distinguish between profiles of different shapes [24, 25].

Air permeability properties of the fabrics were measured on Textest AG FX 3300 air permeability tester according to ISO 9237 standard with five repetitions for each fabric sample [26]. Thermal resistance values of the fabrics were measured by SDL-Atlas Sweating Guarded Hotplate according to ISO 11092 [27].

The moisture management tester (MMT), which is used in the experiment, is an instrument to test the liquid moisture management capabilities of textiles according to AATCC 195 [28]. The MMT instrument consists of upper and lower concentric moisture sensors, where the fabric being tested is placed in between two sensors. When moisture is transported in a fabric, the contact electrical resistance of the fabric changes and the measured electrical resistance are related to the water content in the fabric [29-31]. By using MMT instrument, wetting time, absorption rate, maximum wetted radius, spreading speed, and overall moisture management capacity (OMMC) of the fabrics were measured. Wetting times WTT $_{\text {top }}$, WTB $_{\text {bottom, }}$ can be defined as the time periods in which the top and bottom surfaces of the fabric just start to get wetted after the commencing of the test, and are expressed in seconds when the slope of total water contents at the top and bottom surfaces become greater than $\tan 15^{\circ}$, respectively. Absorption rate $\left(\mathrm{TAR}_{\text {top }}, \mathrm{BAR}_{\text {bottom }}\right)$ is average moisture absorption ability of the fabric in the pump time. Maximum wetted radius, $M W R_{\text {top }}$ and $M W R_{\text {bottom }}$, is defined as the maximum wetted ring radii at the top and bottom surfaces, respectively, where the slopes of water content become greater than $\tan 15^{\circ}$ for the top and
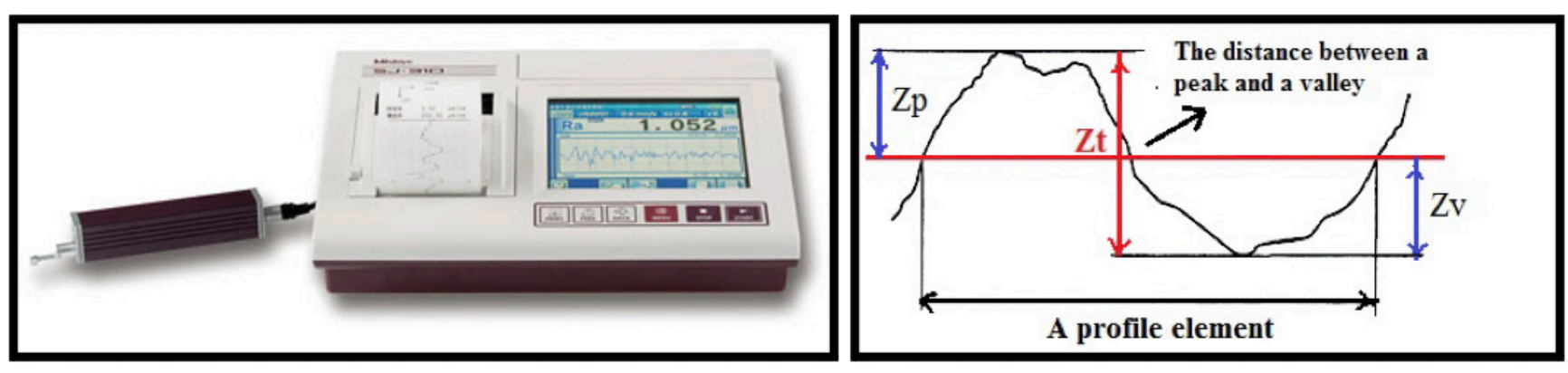

(a)

(b)

Figure 2. (a) Surftest roughness instrument and (b) profile element $(Z(x)$ : the ordinate value, the height of the profile in each position of $x$ from the mean line). 
bottom surfaces, respectively. Spreading speed SS $_{\text {top }}$ and $\mathrm{SS}_{\text {bottom }}$ ) is defined as the accumulative spreading speed from the center to the maximum wetted radius $(\mathrm{mm} / \mathrm{sec})$.

OMMC is an index to indicate the overall ability of the fabric in managing the transport of liquid moisture, which includes three aspects of performance: moisture absorption rate of the bottom side, one-way liquid transport ability, and moisture drying speed of the bottom side, which is represented by the maximum spreading speed. The larger the OMMC is the higher the overall moisture management ability of the fabric [31].

Taguchi's orthogonal array and variance analysis were applied after each test to find optimum levels of control parameters that have effects on fabric. Obtained results are significant at $\alpha=$ 0.05 level according to Taguchi method. Thus, if $p \leq \alpha$, it means that the related parameter has a significant effect on the result; if $p>\alpha$, the related parameter does not have an effect on the test result.

\section{Results and discussion}

Circular bending rigidity values of the fabrics and main effects plot for each process variable were presented in Figure 3. When the results were examined in detail, weaving process variables such as bottom layer, number of interlacing warps in a unit report, and number of interlacing picks per warp had a statistically significant effect on the circular bending rigidity of the fabrics (Table 3). When the importance level of each factor on circular bending rigidity was considered (Table 3 ), the most effective parameter was found to be the number of interlacing warps in a unit report $(\Delta=1.228)$. As the number of interlacing warps in a unit report increased, the circular bending rigidity of the double-layered fabrics also increased due to tight structure obtained. The second important parameter was the number of interlacing picks per warp yarn $(\Delta=0.694)$. Increasing both the number of interlacing picks per warp yarn and number of weft skips resulted in longer floats which produced a loose structure in the double- layered woven fabric structure. Thus, increasing the number of interlacing picks per warp yarn caused a decrease in the circular bending rigidity of the double-layered woven fabrics. Based on the bottom layer patterns, the lowest circular bending rigidity values were obtained with panama and the highest values were with ribs $2 / 2$. Since these two patterns are derivatives of plain weave, it is thought that long floats with more than one warp yarn made the fabrics softer which caused low circular bending rigidity values.

Average roughness $\left(R_{a}\right)$, the sum of the maximum profile peak height and the valley depth of the fabrics $\left(R_{z}\right)$ values and main effects plot for each process variable were presented in Figure 4.Based on the bottom layer pattern, the highest roughness values were obtained with panama fabrics. In the production of double-layered woven fabrics, the ones having panama pattern in bottom layer was produced with lower pick density (26 picks $/ \mathrm{cm}$ ) compared to the others, therefore this weft density made the fabrics looser compared to those produced with 28 picks $/ \mathrm{cm}$. Thus, surface roughness of the panama fabrics was higher than twill and ribs constructed fabrics. There was no statistically significant effect in the process variables such as bottom layer, number of interlacing warps in a unit report,

Table 3. Variance analysis and importance level of each factor on circular bending

\begin{tabular}{|c|c|c|}
\hline \multirow{2}{*}{ Variance source } & \multicolumn{2}{|c|}{ Circular Bending } \\
\cline { 2 - 4 } & $\mathbf{p}$ & $\Delta$ \\
\hline Bottom layer & $\mathbf{0 . 0 0 0}$ & 0.656 \\
\hline Number of interlacing warps in a unit report & $\mathbf{0 . 0 0 0}$ & 1.228 \\
\hline Number of interlacing picks per warp & $\mathbf{0 . 0 0 0}$ & 0.694 \\
\hline Number of weft skips & 0.196 & 2 \\
\hline
\end{tabular}

$\mathrm{p}, \Delta$, and $\mathrm{R}$ : used for probability, difference, and ranking respectively. $\mathrm{p}$ values in bold means that the parameter has a statistically significant effect.
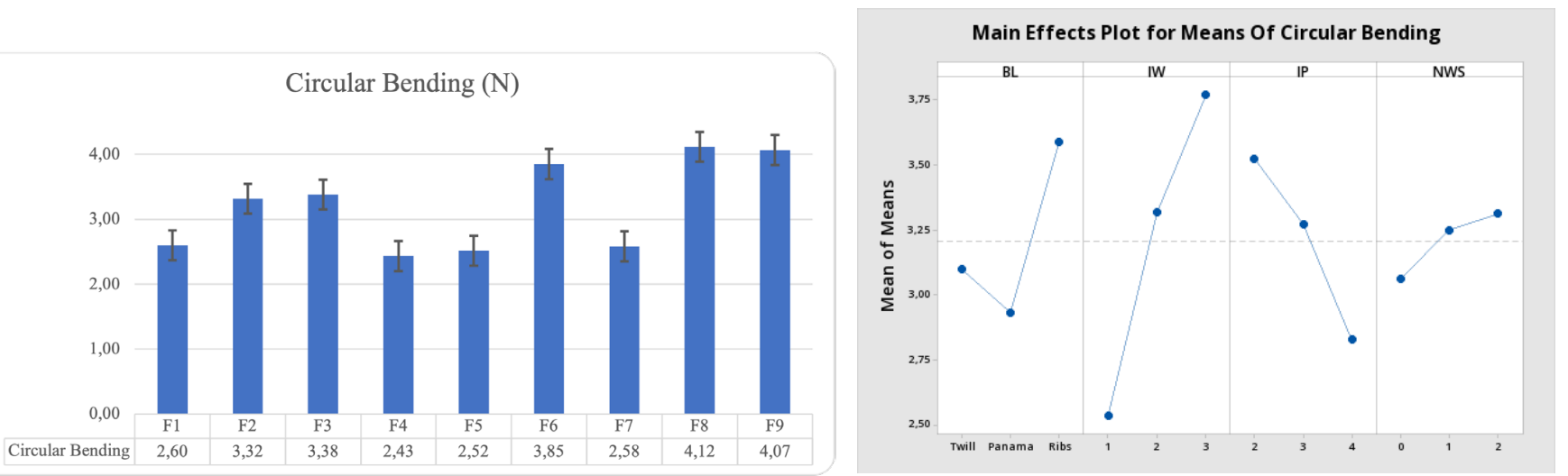

Figure 3. Circular bending results and main effects of the parameters on circular bending of the fabrics (BL: Bottom layer, IW: Number of interlacing warps in a unit report, IP: number of interlacing picks per warp, NWS: number of weft skips). 
number of interlacing picks per warp, and number weft skips (Table 4). Increasing the number of interlacing warps in a unit report was expected to reduce the surface roughness $\left(R_{z}\right)$ due to tighter or stiffer structure. However, increasing this process variable increased the maximum peak height and maximum valley depths due to the connection between the top layer warp and the bottom layer weft. As the number of interlacing picks increased, surface roughness values of the fabrics decreased. This rougher fabric surface may be due to the result of the longer floats, however increasing the number of interlacing picks makes the fabric smoother. Increasing the number of weft skips caused longer floats which resulted in higher $R_{z}$ values as expected.

Average air permeability results of the fabrics and main effects plot for each process variables were presented in Figure 5, and variance analysis and importance level of each factor were given in Table 5. According to the statistical analysis, all weaving parameters had a significant effect on the air permeability properties of the fabrics. Bottom layer had a higher importance level of four and the most air permeable fabrics were composed of panama patterns $(\Delta=19.23)$. The reason of supplying more permeable structure with the panama fabrics in bottom layer was due to the low pick density. As it was mentioned, these fabrics had low pick densities that caused more porous structure. As expected, increasing the number of interlacing warps in a unit report affected the air permeability of the fabrics negatively. This parameter had also an important influence on the air permeability of the fabrics $(\Delta=39.76)$. Increasing the number of warps in a unit report made a tighter structure which decreased the air permeability of the fabrics.
The most important parameter was number of interlacing picks per warp $(D=42.35)$. As the number of interlacing picks per warp yarn was increased, it was expected that the air permeability of the fabrics would be increased due to the increased number of intersections. However, this parameter has to be considered along with the number of weft skips. Increasing both the number of interlacing picks per warp and number of weft skips made longer floats which caused an increase in the air permeability of the fabrics.

Thermal resistance values of the fabrics and main effects plot for each process variable were presented in Figure 6, and variance analysis and importance level of each factor were given in Table 6.

As given in Table 6, thermal resistance rates of the fabrics measured by Hot plate instrument were affected by all parameters investigated here significantly. Bottom layer pattern, number of interlacing picks per warp, number of interlacing warps in a unit report, and number of weft skips were respectively important parameters according to calculated ranking $(\Delta)$ values. However, the differences that were caused based on the investigated parameters were very low, and this difference can be neglected at all in practice. The maximum $\Delta$ value was 0.0054 which was approximately $6 \%$ of the thermal resistance value, caused by the differences in bottom layer pattern. Generally, thermal resistance of the fabrics is influenced mainly by the fabric thickness and thermal conductivity. As the materials used to produce fabrics were the same, the only parameters that changed the thermal resistances of the fabrics were the weaving parameters.

Table 4. Variance analysis and importance level of each factor on roughness results

\begin{tabular}{|c|c|c|c|c|c|c|}
\hline \multirow[b]{2}{*}{ Variance Source } & \multicolumn{3}{|c|}{ Max. height and valley depth $\left(R_{z}\right)$} & \multicolumn{3}{|c|}{ Average roughness $\left(R_{\mathrm{a}}\right)$} \\
\hline & $p$ & $\Delta$ & $\boldsymbol{R}$ & $p$ & $\Delta$ & $R$ \\
\hline Bottom layer & 0.690 & 11.8 & 3 & 0.795 & 2.35 & 2 \\
\hline Number of interlacing warps in a unit report & 0.134 & 30.8 & 1 & 0.079 & 7.57 & 1 \\
\hline Number of interlacing picks per warp & 0.307 & 22.4 & 2 & 0.882 & 1.52 & 3 \\
\hline Number of weft skips & 0.909 & 5.8 & 4 & 0.920 & 1.35 & 4 \\
\hline
\end{tabular}

$p, \Delta$, and $R$ : used for probability, difference, and ranking respectively. $p$ values in bold means that the parameter has a statistically significant effect.

Table 5. Variance analysis and importance level of each factor on air permeability of the fabrics

\begin{tabular}{|c|c|c|c|}
\hline \multirow[b]{2}{*}{ Variance Source } & \multicolumn{3}{|c|}{ Air permeability } \\
\hline & $p$ & $\Delta$ & $\boldsymbol{R}$ \\
\hline Bottom Layer & 0.000 & 19.23 & 4 \\
\hline Number of interlacing warps in a unit report & 0.000 & 39.76 & 2 \\
\hline Number of interlacing picks per warp & 0.000 & 42.35 & 1 \\
\hline Number of weft skips & 0.000 & 30.57 & 3 \\
\hline
\end{tabular}

$p, \Delta$, and $R$ : used for probability, difference, and ranking respectively. $p$ values in bold means that the parameter has a statistically significant effect. 

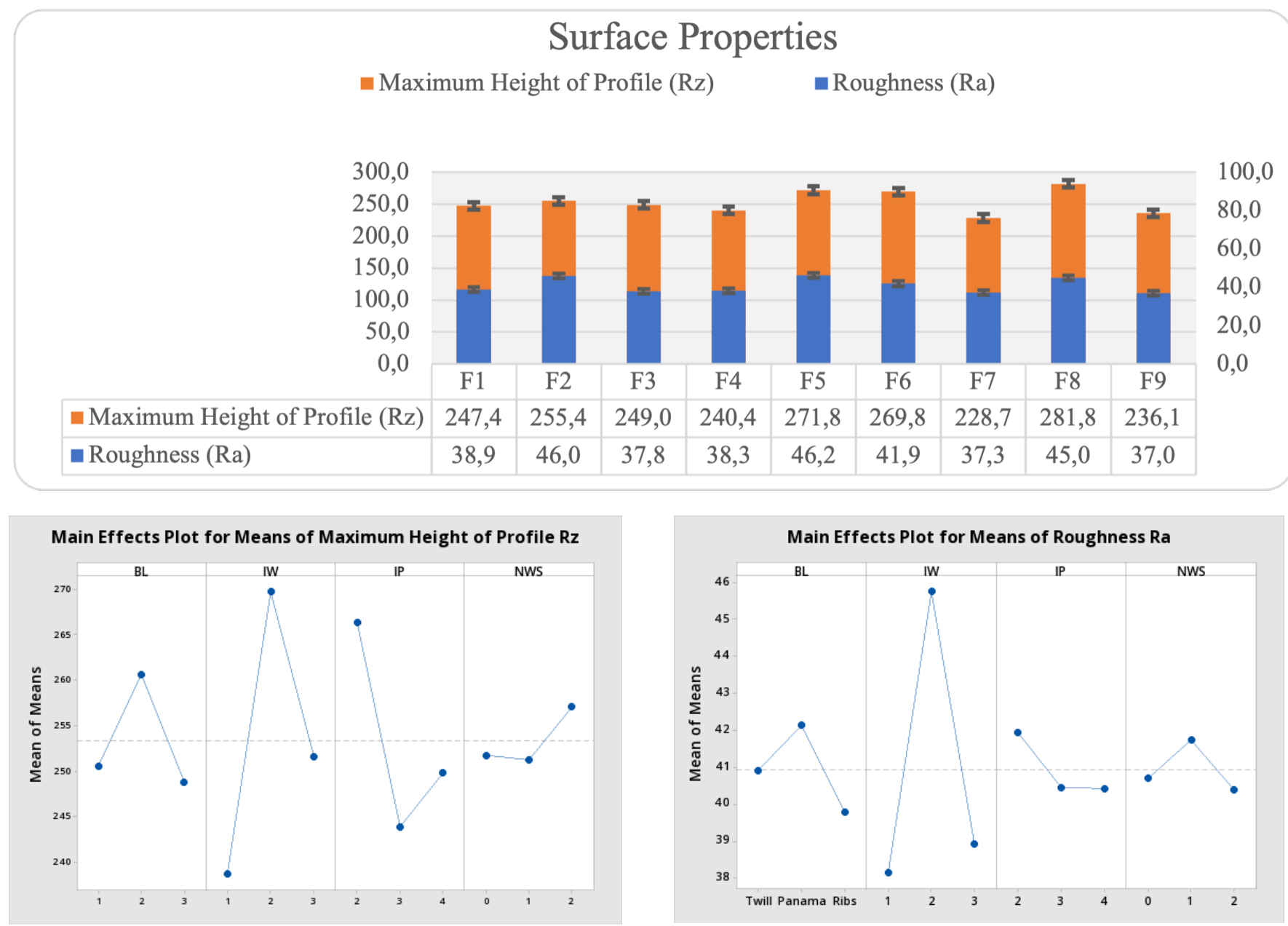

Figure 4. Roughness $R_{\mathrm{a}}$ and $R_{\mathrm{z}}$ results and main effects of the parameters on roughness of the fabrics (BL: Bottom layer, IW: Number of interlacing warps in a unit report, IP: number of interlacing picks per warp, NWS: number of weft skips).

However, the thickness values of the fabrics were almost the same after stentering. Therefore, the only parameter affecting the thermal resistance of the fabrics was thermal conductivity. As the fabric thickness values and the temperature difference were the same, the only parameter that influenced the thermal conductivity was heat flux $(q)$. Heat flux can be defined as the energy flow per unit area per unit time. Since the material used to produce the all fabrics were the same, the only difference that would make change in the heat flux values would depend on the weaving parameters.
Liquid transport properties of the fabrics measured by MMT were given in Table 7 .

When the OMMC values of the fabrics compared with the grading table given by the manufacturing company $(0-0.2$ : very poor, 0.2-0.4: poor, 0.4-0.6: good, 0.6-0.8: very good, $>0.8$ : excellent), all the fabrics were in the "poor" category in terms of moisture management capacity except F1 which was categorized as moisture management fabric according to MMT Manual. All the other fabrics were evaluated as slow absorbing and slow drying or water proof fabrics. Based on the

Table 6. Variance analysis and importance level of each factor on thermal resistance of the fabrics

\begin{tabular}{|c|c|c|}
\hline & \multicolumn{2}{|c|}{ Thermal resistance } \\
\hline Variance Source & $\boldsymbol{p}$ & $\Delta$ \\
\hline Bottom layer & $\mathbf{0 . 0 0 0}$ & 0.0054 \\
\hline Number of interlacing warps in a unit report & $\mathbf{0 . 0 0 0}$ & 0.0045 \\
\hline Number of interlacing picks per warp & $\mathbf{0 . 0 0 0}$ & 0.0046 \\
\hline Number of weft skips & $\mathbf{0 . 0 0 0}$ & 0.0023 \\
\hline
\end{tabular}

$p, \Delta$, and $R$ : used for probability, difference, and ranking respectively. $p$ values in bold means that the parameter has a statistically significant effect. 

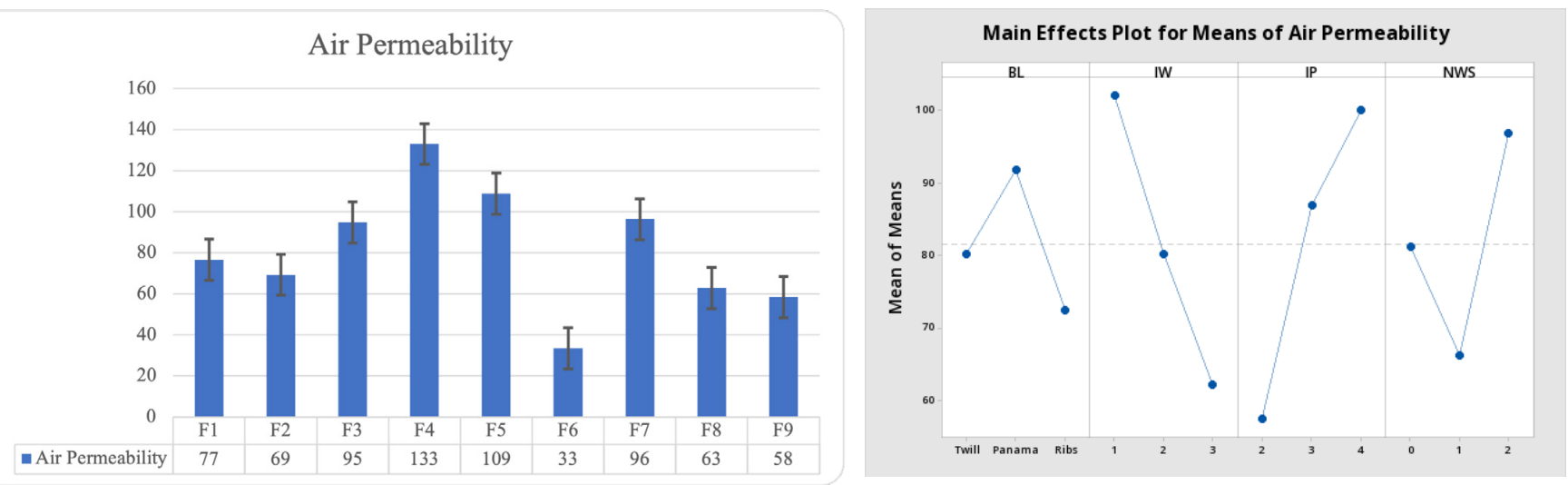

Figure 5. Air permeability results (It $\left./ \mathrm{m}^{2} . \mathrm{s}\right)$ and main effects of the parameters on air permeability of the fabrics (BL: Bottom layer, IW: Number of interlacing warps in a unit report, IP: number of interlacing picks per warp, NWS: number of weft skips).

Table 7. The results of the measurements on Moisture management tester

\begin{tabular}{|c|c|c|c|c|c|c|c|c|c|}
\hline & $\begin{array}{c}\text { Top } \\
\text { wetting } \\
\text { time (s) }\end{array}$ & $\begin{array}{c}\text { Top } \\
\text { absorption } \\
\text { rate }(\% / s)\end{array}$ & $\begin{array}{c}\text { Top max } \\
\text { wetted } \\
\text { radius } \\
\text { (mm) }\end{array}$ & $\begin{array}{l}\text { Top } \\
\text { spreading } \\
\text { speed } \\
(\mathrm{mm} / \mathrm{s})\end{array}$ & $\begin{array}{l}\text { Bottom } \\
\text { wetting } \\
\text { time (s) }\end{array}$ & $\begin{array}{c}\text { Bottom } \\
\text { absorption } \\
\text { rate }(\% / s)\end{array}$ & $\begin{array}{l}\text { Bottom } \\
\text { max wetted } \\
\text { radius } \\
(\mathrm{mm})\end{array}$ & $\begin{array}{l}\text { Bottom } \\
\text { spreading } \\
\text { speed } \\
(\mathrm{mm} / \mathrm{s})\end{array}$ & OMMC \\
\hline F1 & 2.89 & 28.3 & 25.00 & 5.01 & 3.2 & 47.50 & 23.33 & 4.95 & 0.59 \\
\hline $\mathrm{F} 2$ & 13.93 & 9.8 & 5.00 & 0.76 & 18.7 & 5.07 & 0.00 & 0.00 & 0.09 \\
\hline F3 & 119.95 & 0.0 & 0.00 & 0.00 & 120.0 & 0.00 & 0.00 & 0.00 & 0.08 \\
\hline F4 & 5.14 & 9.8 & 21.67 & 3.64 & 11.2 & 11.98 & 18.33 & 3.33 & 0.31 \\
\hline F5 & 22.39 & 5.5 & 8.33 & 0.45 & 12.9 & 15.49 & 8.33 & 1.84 & 0.24 \\
\hline F6 & 53.77 & 2.1 & 0.00 & 0.00 & 86.5 & 0.97 & 0.00 & 0.00 & 0.09 \\
\hline $\mathrm{F} 7$ & 81.50 & 5.8 & 6.67 & 1.10 & 8.4 & 8.12 & 10.00 & 1.31 & 0.18 \\
\hline F8 & 119.95 & 0.0 & 0.00 & 0.00 & 86.4 & 1.28 & 0.00 & 0.00 & 0.07 \\
\hline F9 & 119.95 & 0.0 & 0.00 & 0.00 & 120.0 & 0.00 & 0.00 & 0.00 & 0.08 \\
\hline
\end{tabular}

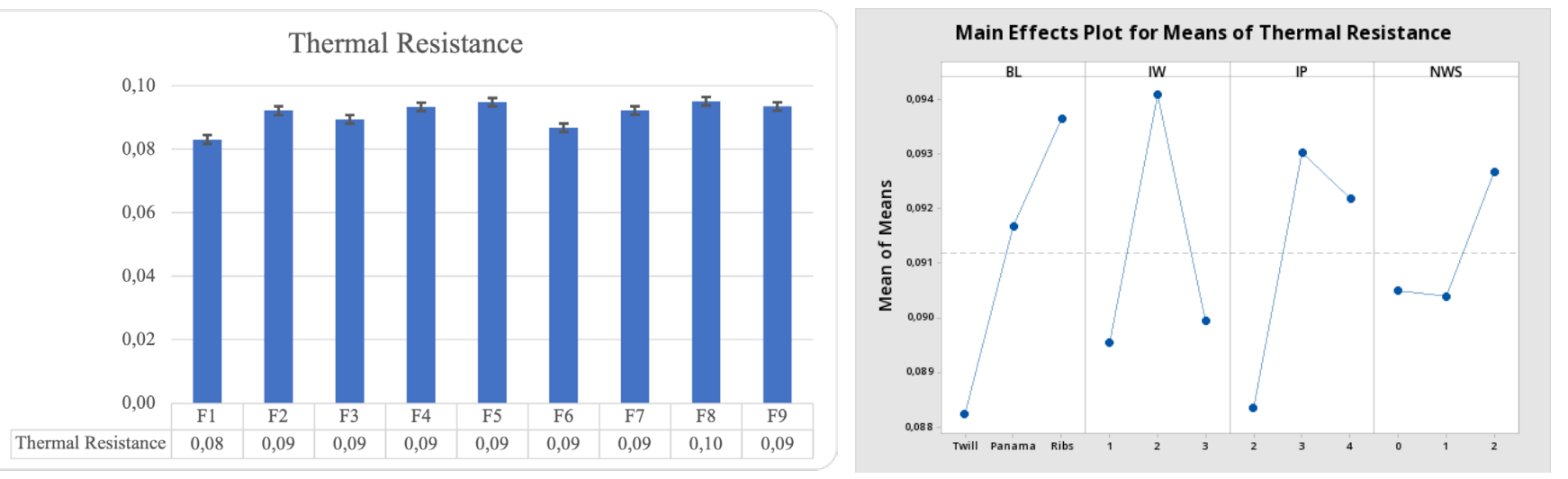

Figure 6. Thermal resistance results $\left(\mathrm{m}^{2} . \mathrm{K} / \mathrm{W}\right)$ and main effects of the parameters on thermal resistance of the fabrics (BL: Bottom layer, IW: Number of interlacing warps in a unit report, IP: number of interlacing picks per warp, NWS: number of weft skips).

statistical analysis, main effects of the weaving parameters and their importance were presented in Figure 7 and Table 8, respectively.

\section{CONCLUSIONS}

In this study, double-layered woven fabrics were produced from 450 denier polyester yarns, of which upper layer was produced as Twill $2 / 2 \mathrm{Z}$ which is commonly used in automotive seat upholstery. Four different parameters were used in the production of fabrics, which were bottom layer pattern, number of interlacing warps in a unit report, number of interlacing picks 


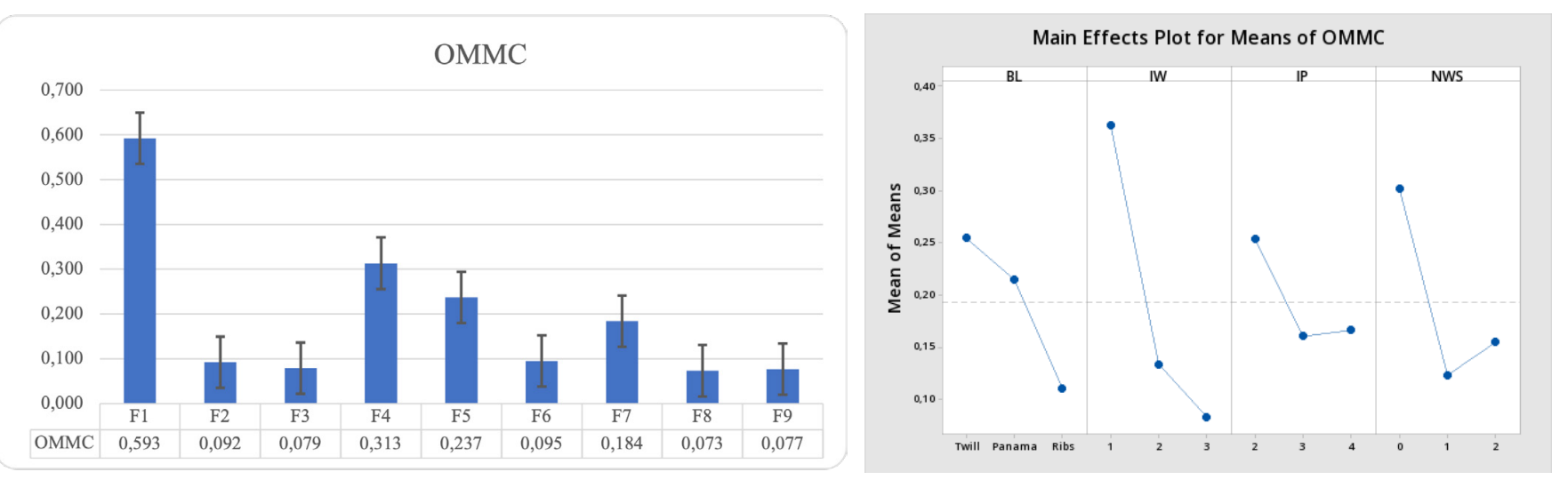

Figure 7. OMMC results and main effects of the parameters on OMMC results of the fabrics (BL: Bottom layer, IW: Number of interlacing warps in a unit report, IP: number of interlacing picks per warp, NWS: number of weft skips).

Table 8. Variance analysis and importance level of each factor on OMMC of the fabrics

\begin{tabular}{|c|c|c|}
\hline & \multicolumn{2}{|c|}{ OMMC } \\
\hline Variance source & $\boldsymbol{P}$ & $\boldsymbol{R}$ \\
\hline Bottom Layer & $\mathbf{0 . 0 1 9}$ & 0.143 \\
\hline Number of Interlacing warps in a unit report & $\mathbf{0 . 0 0 0}$ & 0.280 \\
\hline Number of interlacing picks per warp & 0.116 & 0.090 \\
\hline Number of weft skips & $\mathbf{0 . 0 0 3}$ & 0.178 \\
\hline
\end{tabular}

$p, \Delta$, and $R$ : used for probability, difference, and ranking respectively. $p$ values in bold means that the parameter has a statistically significant effect.

per warp, and number of weft skips. After weaving stage, the fabrics were fixed on a stenter. Based on the performed measurements, the following results were obtained;

All the investigated parameters except number of weft skips have statistically significant effect on the circular bending rigidity of the fabrics. Among these parameters, the most effective one was found to be number of interlacing warps in a unit report. Since bending rigidity is related to the handle characteristics of the fabrics, increased results indicate stiffer structure. Therefore as the number of interlacing warps in a unit report increases, the number of interlacing picks per warp yarn decreases whereas the circular bending rigidity of the fabrics increases, meaning that the handle of the fabrics gets tighter. Due to the long floats, the lowest circular bending rigidity values were obtained with panama construction while the highest values were supplied by ribs $2 / 2$ structure.

The effects of the investigated parameters on the average roughness $\left(R_{a}\right)$ and the sum of the maximum peak height and the valley depth of the fabrics $\left(R_{z}\right)$ were not statistically significant. However, based on the bottom layer pattern, the highest roughness values were obtained with panama fabrics due to the lower weft density when compared to the twill and ribs pattern fabrics. As the number of interlacing picks increases and the number of weft skips decreases, surface roughness of the fabrics decreases due to the longer floats, which means that the fabrics is becoming smoother.
Air permeability of all fabrics was affected by the investigated parameters significantly. Panama structure as bottom layer weaving construction resulted in a more permeable fabric. Increased number of interlacing warps in a unit report and higher number of intersections of picks per warp caused lower air permeability, however when the number of interlacing picks per warp and number of weft skips are considered together, the effect changes to increased air permeability due to the longer floats.

All the weaving parameters influenced had a statistically significant effect on the thermal resistance of the fabrics. However, this statistical significant effect was very low in practical usage. Thus, the effects of the weaving parameters were suppressed after stentering process.

In terms of liquid transport properties measured by MMT instrument, all the fabrics were in the "poor" category except fabric coded as F1.

\section{Acknowledgement}

We would like to thank Textile Engineer M.Sc.Özgür Avcu who helped in fabric production within the scope of the study. 


\section{References}

[1] Schwarz, I. G., Kovačevic,' S., Kos, I. (2015). Physical mechanical properties of automotive textile materials. Journal of Industrial Textiles, 45(3), 323-337

[2] Fung, W., Hardcastle, M. (2001). Textiles in automotive engineering. Woodhead Publishing Ltd., (Cambridge, England).

[3] Shishoo, R. (2008). Textile advances in the automotive industry. Woodhead Publishing Ltd. (Cambridge, England).

[4] Kovačević, S., Domjanić, J., Brnada, S., Schwarz, I. (2017). Textile composites for seat upholstery, textiles for advanced applications. Intechopen Publishing, pp. 191209. doi: 10.5772/intechopen.68984.

[5] Mukhopadhyay, S. K., Partridge, J. F. (1999). Automotive textiles. Textile Progress, 29(1-2), doi:10.1080/00405169908688876, 1-125.

[6] Singha, K. (2012). Strategies for in automobile: strategies for using automotive textiles-manufacturing techniques and applications. Journal of Safety Engineering, 1(1), 7-16.

[7] Yao, G. (2015). Development of the automobile seat fabric by polyester filament. In: 5th International Conference on Advanced Engineering Materials and Technology (AEMT), 583-586

[8] Jerkovic, I., Pallares, J. M, Capdevila, X. (2010). Study of the abrasion resistance in the upholstery of automobile seats. Autex Research Journal, 10(1).

[9] Havelka, A., Glombikova, V., Komarkova, P., Chotebor, M. (2017). The study of fabric performance for car seats. Tekstilec, 60(3), 235-242.

[10] El-Homossani, M., Gawad, M. A., Khalifa, T. F., Hafez, H. S. (2015). Achieving optimum thermal comfort properties for automotive seat fabrics. International Journal of Advance Research in Science and Engineering, 4(11), 424-435.

[11] Simiona, M., Socaciua, L., Unguresana, P. (2016). Factors which influence the thermal comfort inside of vehicles. Energy Procedia, 85, 472-480.

[12] Yahya, M. F. (2002). Abrasion and tensile relationships of automotive car seat fabrics (Master's thesis). School of Textiles and Design. The University of Leeds.

[13] Pamuk, G., Çeken, F. (2008). Comparative study of the abrasion resistance of automobile seat covers. Fibres \& Textiles in Eastern Europe, 16(4), 57-61.

[14] Ujević, D., Kovačević, S., Wadsworth, L. C., Schwarz, I., Šajatović, B. B. (2009). Analysis of artificial leather with textile fabric on the backside. Journal of Textile and Apparel, Technology and Management, 6(2), 1-9.
[15] Cengiz, T. G.,, Babalık, F. C. (2009). The effects of ramie blended car seat covers on thermal comfort during road trials. International Journal of Industrial Ergonomics, 39, 287-294. doi:10.1016/j.ergon.2008.12.002.

[16] Jerkovic, I., Pallarés, J. M., Ardanuy, M., Capdevila, X. (2013). Abrasive elements and abrasion resistance tests for car. Journal of Engineered Fibers and Fabrics, 8, 35-41.

[17] Mecit, D., Berber, R. O., Boyacı, B. (2015). A study on the application of recycled fabrics as automotive seat upholstery. Industria Textila, 5, 278-282.

[18] Koc, S. K., Mecit, D., Boyaci, B., Örnek, M., Hockenberger, A. (2016). Effects of filament crosssection on the performance of automotive up holstery fabrics. Journal of Industrial Textiles, 46(3), 756-770. doi: 10.1177/1528083715598652.

[19] Avcu, Ö., Gürkan Ünal, P. (2018). Mechanical properties of doublelayered woven fabrics used in car seat upholstery. The Journal of the Textile Institute, 109(11), 1409-1417. doi: 10.1080/00405000.2018.1423901.

[20] El Mogahzy, Y. E. (2009). Engineering textiles integrating the design and manufacture of textile products. Woodhead Publishing (Cambridge, England).

[21] ASTM D 4032, Standard Test Method for Stiffness of Fabric by the Circular Bend Procedure.

[22] ISO 4287, Geometrical Product Specifications (GPS) Surface texture: Profile method - Terms, definitions and surface texture parameters

[23] MitutoyoSurftest J-310 Manual, 2010.

[24] Mooneghi, S. A., Varkiyani, S. M. H. (2014). Surface roughness evaluation of textile fabrics: A literature review. Journal of Engineered Fibers and Fabrics, 9(2), 1-18.

[25] Mooneghi. S. A., Varkiyani. S. M. H. (2015). Study on fabric surface roughness and its influence on worsted fabric abrasion resistance. Journal of Engineered Fibers and Fabrics, 10(4), 79-86.

[26] ISO 9237, Textiles - Determination of the permeability of fabrics to air.

[27] ISO 11092, Textiles - Physiological effects - Measurement of thermal and water-vapour resistance under steady-state conditions (sweating guarded-hotplate test).

[28]AATCC Test Method (TM) 195, Liquid Moisture Management Properties of Textile Fabrics.

[29] Hu, J., Li, Y., Yeung, K., W. Wong, A. S. W., Xu, W. (2005). Moisture management tester: $A$ method to characterize fabric liquid moisture management properties. Textile Research Journal, 75(1), 57-62.

[30] Li, Y., Xu, W., Yeung, K. W. (2000), Moisture Management of Textiles, U.S. patent 6,499,338 B2

[31] Moisture Management Tester Operation Manual, 2012. 